\title{
Macronutrient distribution over a period of 23 years in relation to energy intake and body fatness
}

\author{
Lando L. J. Koppes ${ }^{1,2,3 *}$, Niels Boon ${ }^{4}$, Astrid C. J. Nooyens ${ }^{2,5}$, Willem van Mechelen ${ }^{1,2}$ \\ and Wim H. M. Saris ${ }^{4}$ \\ ${ }^{1}$ EMGO Institute, VU University Medical Center, Amsterdam, The Netherlands \\ ${ }^{2}$ Department of Public and Occupational Health, VU University Medical Center, Amsterdam, The Netherlands \\ ${ }^{3}$ Division of Work and Employment, TNO Quality of Life, PO Box 718, Hoofddorp 2130 AS, The Netherlands \\ ${ }^{4}$ Nutrition and Toxicology Research Institute Maastricht (NUTRIM), University of Maastricht, Maastricht, The Netherlands \\ ${ }^{5}$ Institute of Health Sciences, Faculty of Earth and Life Sciences, Vrije Universiteit Amsterdam, Amsterdam, The Netherlands \\ (Received 28 August 2007 - Revised 11 February 2008 - Accepted 25 March 2008 - First published online 9 May 2008)
}

The distribution of the four macronutrients is associated with energy intake and body fatness according to short-term interventions. The present study involves macronutrient distribution in relation to energy intake and body fatness over a period of 23 years in individuals who have ad libitum access to food. Eight follow-up measurements have been performed in 168 men and 182 women who participate in the Amsterdam Growth and Health Longitudinal Study. From the age of 13 years onwards, dietary intake, physical activity and the thickness of four skinfolds have been assessed. Body fatness was assessed using dual-energy X-ray absorptiometry at the age of 36 years. Generalised estimating equation regression analyses showed that energy percentages $(\mathrm{En} \%)$ from protein and (in men) carbohydrates were inversely related to energy intake, while the En\% from fat was positively related with energy intake. The men and women with high body fatness at the age of 36 years had a 1 En\% higher protein intake, and the women with high body fatness had a $2 \mathrm{En} \%$ lower alcohol intake at the age of 32 and 36 years. The apparent inconsistent relationships between protein and energy intake and protein and body fatness can in women be explained by reverse causation and underreporting, as in women, low energy intake could not be explained by low physical activity. In conclusion, high intake of protein and (in men) carbohydrate, and low intake of fat are inversely related to total energy intake. High body fatness at the age of 36 years is related to a higher protein intake and, in women, to a lower alcohol intake.

Macronutrient distribution: Energy intake: Body fatness: Adolescence to adulthood follow-up: Long-term longitudinal studies

Obesity, the excess of body fatness, is an increasingly important worldwide public health problem ${ }^{(1)}$. A misbalance between energy intake and energy expenditure causes obesity. The relative amounts consumed of the four macronutrients also matters ${ }^{(2)}$. Recently, more attention has been given to protein because high-protein diets have been found to be inversely related to obesity ${ }^{(3-7)}$. Protein is known to cause a higher diet-induced thermogenesis per $\mathrm{kJ}$ than fats or carbohydrates, leading to a lower metabolic efficiency ${ }^{(8-10)}$. The synthesis of peptide bonds, the production of urea and gluconeogenesis are all metabolic processes with a high energy requirement that are elevated by the consumption of a highprotein diet ${ }^{(8,11)}$. High-protein diets have also been reported to increase satiety ${ }^{(12-14)}$. This satiety effect may be mediated by cholecystokinin, as in rodents, a high-protein diet induces increased cholecystokinin production ${ }^{(15)}$, and cholecystokinin has been linked to an increased satiety in humans ${ }^{(16)}$.

Protein has been used in experimental studies on bodyweight regulation ${ }^{(3-7)}$. These trials show that an increase in protein intake reduces body weight in subjects consuming an ad libitum or isoenergetic diet. In addition, after weight loss high-protein diets reduced weight regain ${ }^{(14)}$. These trials, however, concern relatively short-term interventions whereas the more long-lasting changes in body weight are those that develop slowly over longer periods of time. In addition, these trials are not performed in general populations, whereas the general population is where the obesity pandemic is developing at the moment.

The other three macronutrients (fat, carbohydrate and alcohol) also play a role in body-weight regulation. Several studies have shown that a relative reduction of either the carbohydrate $^{(17-19)}$ or the fat intake $e^{(20,21)}$ in parallel with an increased protein intake could have weight-lowering effects. Furthermore, the energy intake from alcohol has been shown to have J-shaped relationships with body-weight indices ${ }^{(22,23)}$. So, changes in the relative consumption amounts of protein, carbohydrates, fats and alcohol may have an effect on body weight and the amount of body fat.

There are only a few observational studies of sufficient quality in which the association between macronutrient intake and 
body composition was studied in a general population. In one study, a total energy intake-adjusted higher intake of protein and fat was associated with a higher $\mathrm{BMI}^{(24)}$. This finding is in contrast with the results from the intervention studies mentioned above. In three other observational studies, dietary fat intake was associated with body composition under certain conditions. Heitmann et al. ${ }^{(25)}$ observed that a higher fat intake was associated with weight gain only in obese women with a genetic disposition ${ }^{(25)}$. The same group also showed that dietary fat intake was associated with body-weight gain in sedentary women but not in women with an active lifestyle ${ }^{(26)}$. In a more recent paper about the Nurses' Health Study, total fat intake had a weak positive association with body-weight change, whereas significant associations were observed for animal, saturated and trans fat ${ }^{(27)}$.

In the present study we investigate if the relative amounts of intake of the various macronutrients are related to body fatness in a cohort of adolescents who were followed with repeated measurements over a period of 23 years until the age of 36 years. In addition, we will compare the development over those 23 years of the relative consumption amounts of the four macronutrients for men and women with and for those without high body fatness at adult age.

\section{Subjects and methods}

\section{Subjects and design}

In 1977, the Amsterdam Growth and Health Longitudinal Study (AGAHLS) started with assessments on a wide range of characteristics in boys and girls aged 13 (SD 0.7) years. They were all first- and second-year pupils from two equally large secondary schools in The Netherlands. In the pupils from the one school, follow-up measurements were performed in 1978, 1979, 1980, 1985, 1991, 1996 and 2000 when the participants had a mean age of 14, 15, 16, 21, 27, 32 and 36 years, respectively. The pupils from the other school were assessed only once in the first 4 years of the study, and were reassessed in 1996 and 2000 only. In total, 698 13-year-old pupils were included in the AGAHLS of whom 350 (168 men and 182 women) have complete data of the follow-up measurements that were performed 23 years later at the age of 36 years. Girls who completed the 23-year follow-up had a slightly lower body fat percentage at baseline than those who dropped out, and boys who completed the study had lower tobacco and alcohol use at baseline. The AGAHLS was approved by the medical ethics committee of the VU University Medical Center (Amsterdam, The Netherlands). The exact design and methods of the AGAHLS have been described in detail previously ${ }^{(28)}$.

\section{Dietary intake and physical activity}

An extensive cross-check dietary history interview was administered at each follow-up ${ }^{(29)}$. This interview provides information about the habitual dietary intake of the participants using the 4 weeks preceding the interview as a reference. The interview consisted of two parts. The first part focused on drawing a pattern of the participants' eating habits and meal patterns and in the second part an extensive checklist was used to give a more detailed description of all of the food and drink items consumed. The 'cross-check' indicates that additional checks were performed on the items mentioned in the second part of the interview. This was a traditional face-to-face interview during the first seven measurements, whereas during the last measurement at the mean age of 36 years, a computer-assisted method was used. The addition of the computer assistance was done in order to decrease the interview time and to decrease the between-interviewer variability. This computer-assisted cross-check dietary history interview was of similar quality to the traditional face-to-face interview $^{(30)}$. The relative validity of the traditional face-toface interview was shown to be adequate in comparison with $3 \mathrm{~d}$ weighed food record and $24 \mathrm{~h}$ dietary recall methods $^{(29)}$, but was not validated using more objective measures of energy intake or protein intake. The mean daily intake of various nutritional factors was calculated using the Dutch Food and Nutrition Table ${ }^{(31)}$.

As with the dietary intake assessment, for physical activity a traditional face-to-face interview was used during the first seven measurements, whereas a computer-assisted method was used during the last measurement. In the interview, the metabolic component was scored by multiplying the intensity, duration and frequency of the physical activities performed ${ }^{(32)}$.

\section{Body fatness}

At each year of measurement, the thickness of four skinfolds (biceps, triceps, subscapular and cresta iliaca) was assessed according to standard procedures ${ }^{(33)}$. At the last measurement, at the age of 36 years, whole-body dual-energy X-ray absorptiometry (Hologic QDR-2000, software version V5.67A; Hologic Inc., Waltham, MA, USA) was used to assess body fat percentage. Participants were classified as having high body fatness if their percentage body fat at this age-36 measurement exceeded $25 \%$ for men or $35 \%$ for women.

\section{Analyses}

Sex-specific inter-period Pearson's correlation coefficients were calculated for the energy percentages (En\%) from protein, fat, carbohydrates and alcohol, and for total energy intake, physical activity and the sum of the four skinfolds. To obtain inter-measurement periods with a relatively comparable length, the data obtained at the mean age of 14 and 15 years were not taken into account in these tracking analyses. Sex- and follow-up-specific standardised values were calculated for total energy intake, physical activity and the sum of the four skinfolds. This standardisation enabled the use of data from all eight follow-ups in one longitudinal analysis by excluding bias due to follow-up-associated correlations between the mean values of the sample. Generalised estimating equation analyses with an exchangeable correlation structure were used to study the relationships of the En\% from the four macronutrients with total energy intake, the physical activity level and with the sum of the four skinfolds. These analyses are adjusted for age, level of education (at age 36 years) and smoking (yes or no). The analyses with total energy intake and sum of skinfolds are additionally adjusted for the physical activity level, and the analyses with physical activity are additionally adjusted for total energy intake. Total energy intake is a presumed mediator of the hypothesised causal path between the relative energy contributions of the 
macronutrients and the sum of skinfolds, and should therefore not be adjusted for. Generalised estimating equation analyses are longitudinal regression analyses that take into account that repeated measurements on the same individual are not independent. Other advantages of analysing with generalised estimating equations are that time points do not have to be distributed evenly and that it copes with missing observations by using the actual values of all available data gathered over the 23-year period of follow-up ${ }^{(34)}$.

The development of the En\% from fat, protein, carbohydrates and alcohol from mean age 13 to 36 years for the groups of men and women with high and low body fatness at the age of 36 years was analysed with generalised estimating equations also. Time was treated as a categorical variable to estimate these developments, which are presented graphically. Because these analyses are sensitive to misreporting of dietary energy intake that is selective to body fatness, $t$ tests were used to analyse the differences in energy intake, physical activity and lean body mass between the groups with and without a high percentage of body fat at the age of 36 years. All analyses were performed with SAS software (version 9.13; SAS Institute, Inc., Cary, NC, USA).

\section{Results}

Table 1 shows the inter-period correlations for men and women of the relative contributions to total energy intake of the four macronutrients, together with the inter-period correlations of total energy intake, physical activity and the sum of skinfolds. Moderate tracking was found for the four macronutrients, with inter-period correlations of about $0 \cdot 35-0.60$. Tracking of the En\% from alcohol showed a strong increase with the increase of the age of the participants. Overall, tracking of the four macronutrients was slightly smaller than that for total energy intake. Tracking was highest for the sum of skinfolds, and was lowest for physical activity.

Table 2 shows that the longitudinal development of the relative amount of protein intake was inversely related to the longitudinal development of total energy intake. A $1 \%$ higher energy intake in the form of protein was related to a $0.125 \mathrm{SD}$ lower total energy intake in men, and to a $0.152 \mathrm{SD}$ lower energy intake in women. The 23 -year development of the relative amount of fat intake was positively related to total energy intake, in a way that a $1 \%$ higher relative energy contribution in the form of fat was related to a 0.039 and 0.042 SD higher energy intake in men and women, respectively. The En\% from carbohydrates was inversely related to total energy intake in men, whereas the En\% from alcohol was not related to total energy intake.

With regard to the longitudinal development of physical activity, a significant relationship was found only in women for the relative energy intake in the form of alcohol. A $1 \%$ higher relative contribution in the form of alcohol was related to a 0.034 SD lower physical activity level. None of the macronutrients showed a significant relationship with the sum of the four skinfolds.

At the age of 36 years, forty-nine of the 168 men had a body fat percentage $\geq 25$, and fifty-nine of the 182 women had a body fat percentage $\geq 35$. In men, BMI was 23.8 (SD 2.1) and 27.1 (SD 2.8$) \mathrm{kg} / \mathrm{m}^{2}$ in the groups with low and high body fat percentage, respectively. In women, the respective BMI were 22.1 (SD 2.3) and 26.0 (SD 3.3) $\mathrm{kg} / \mathrm{m}^{2}$. Fig. 1 shows the development from age 13 to 36 years of the relative contributions of the four macronutrients for the men and

Table 1. Inter-period Pearson correlation coefficients of the four macronutrients, total energy intake, physical activity and the sum of skinfolds in men and women followed with repeated measurements from age 13 to 36 years

\begin{tabular}{|c|c|c|c|c|c|}
\hline & \multicolumn{5}{|c|}{ Age (years) } \\
\hline & $13-16$ & $16-21$ & $21-27$ & $27-32$ & $32-36$ \\
\hline \multicolumn{6}{|c|}{ En\% from protein } \\
\hline Men & 0.54 & 0.53 & 0.48 & 0.58 & 0.52 \\
\hline Women & 0.62 & 0.31 & 0.38 & 0.52 & 0.55 \\
\hline \multicolumn{6}{|c|}{ En\% from fat } \\
\hline Men & 0.59 & 0.26 & 0.35 & 0.49 & 0.58 \\
\hline Women & 0.35 & 0.38 & 0.43 & 0.49 & 0.39 \\
\hline \multicolumn{6}{|c|}{ En\% from carbohydrate } \\
\hline Men & 0.54 & 0.26 & 0.46 & 0.55 & 0.61 \\
\hline Women & 0.35 & 0.38 & 0.40 & 0.49 & 0.51 \\
\hline \multicolumn{6}{|c|}{ En\% from alcohol } \\
\hline Men & 0.22 & 0.17 & 0.44 & 0.64 & 0.81 \\
\hline Women & 0.13 & 0.37 & 0.49 & 0.84 & 0.60 \\
\hline \multicolumn{6}{|c|}{ Total energy intake } \\
\hline Men & 0.33 & 0.47 & 0.53 & $0 \cdot 70$ & 0.65 \\
\hline Women & 0.61 & 0.56 & 0.50 & 0.61 & 0.58 \\
\hline \multicolumn{6}{|c|}{ Physical activity } \\
\hline Men & 0.43 & 0.46 & 0.22 & 0.41 & 0.49 \\
\hline Women & 0.45 & 0.18 & 0.42 & 0.11 & 0.39 \\
\hline \multicolumn{6}{|c|}{ Sum of skinfolds } \\
\hline Men & 0.80 & 0.61 & 0.77 & 0.92 & 0.83 \\
\hline Women & 0.77 & 0.63 & 0.67 & 0.74 & 0.85 \\
\hline \multicolumn{6}{|c|}{ Number of subjects $(n)$} \\
\hline Men & $66-68$ & $63-64$ & 63 & $61-63$ & $149-153$ \\
\hline Women & $76-77$ & $71-72$ & $66-70$ & $68-72$ & $171-173$ \\
\hline
\end{tabular}

En\%, energy percentage. 
Table 2. Age-, level of education- and smoking-adjusted longitudinal generalised estimating equation regression coefficients using all available data gathered between the ages of 13 and 36 years of the relative contributions to total energy intake of the four macronutrients (protein, fat, carbohydrate and alcohol) with total energy intake, physical activity and the sum of skinfolds in 168 men and 182 women

\begin{tabular}{|c|c|c|c|c|c|c|c|c|c|c|c|c|}
\hline & \multicolumn{4}{|c|}{ Total energy intake ${ }^{*} \dagger$} & \multicolumn{4}{|c|}{ Physical activity $¥$} & \multicolumn{4}{|c|}{ Sum of skinfolds ${ }^{*} \dagger$} \\
\hline & \multicolumn{2}{|c|}{ Men } & \multicolumn{2}{|c|}{ Women } & \multicolumn{2}{|c|}{ Men } & \multicolumn{2}{|c|}{ Women } & \multicolumn{2}{|c|}{ Men } & \multicolumn{2}{|c|}{ Women } \\
\hline & $\beta$ & $P$ & $\beta$ & $P$ & $\beta$ & $P$ & $\beta$ & $P$ & $\beta$ & $P$ & $\beta$ & $P$ \\
\hline En\% from protein & -0.125 & $<0.001$ & -0.152 & $<0.001$ & 0.006 & 0.75 & 0.012 & 0.44 & 0.015 & 0.27 & 0.018 & 0.18 \\
\hline En\% from fat & 0.039 & $<0.001$ & 0.042 & $<0.001$ & -0.013 & 0.06 & -0.007 & 0.27 & 0.005 & 0.42 & 0.001 & 0.89 \\
\hline En\% from carbohydrates & -0.018 & 0.02 & -0.002 & 0.78 & 0.007 & 0.29 & 0.011 & 0.06 & -0.004 & 0.49 & -0.003 & 0.61 \\
\hline En\% from alcohol & 0.016 & 0.35 & -0.020 & 0.25 & 0.012 & 0.43 & -0.034 & 0.0074 & -0.010 & 0.39 & -0.007 & 0.59 \\
\hline
\end{tabular}

En\%, energy percentage.

* Sex- and year of measurement-specific $Z$-scores were used.

†Associations of macronutrient intake with total energy intake and sum of skinfolds are additionally adjusted for physical activity level.

$\ddagger$ Associations between macronutrient intake and physical activity are additionally adjusted for total energy intake.

women with and without high body fatness at the age of 36 years. Men with high body fatness at the age of 36 years had a significantly higher relative protein intake at the ages of 32 and 36 years as compared with the men without high body fatness (Fig. 1 (a)). Throughout the 23-year period of follow-up, the relative protein intake in women with high body fatness at the age of 36 years was about $1 \%$ higher than in women without high body fatness (Fig. 1 (e)). This difference was statistically significant for the measurements at the ages of 13, 32 and 36 years. The relative energy intake from fat and carbohydrates from age 13 to 36 years were not related to body fatness at the age of 36 years (Figs. 1 (b), (c), (f) and (g)). The relative contribution to total energy intake in the form of alcohol was 1-2\% lower from age 27 years onwards in women with high body fatness at the age of 36 years (Fig. 1 (h)).

Table 3 shows for both men and women that energy intake was lower in the groups with a high body fat percentage. In men, those with a high body fat percentage had a lower physical activity level, whereas lean body mass did not differ between those with and without high body fat percentage. In women, the physical activity level was $20 \%$ higher $(P=0.07)$ and lean body mass was $1.3 \mathrm{~kg}$ lower $(P=0.11)$ in those with high body fat percentage than in those with a low body fat percentage.

\section{Discussion}

In the present study, we have studied the longitudinal associations between the relative intakes of the four macronutrients (protein, fat, carbohydrate and alcohol) with body composition in subjects that have ad libitum access to food. We observed that the intakes of protein and (in men) carbohydrates were inversely associated with total energy intake, and that the intake of fat was positively associated with total energy intake. These findings can be explained by the lower energy density of carbohydrate and protein as compared with fat, because it has been observed that the energy density of the diet is positively related to total energy intake ${ }^{(35)}$.

In both men and women, the association between protein and energy intake was about three times larger than the association between fat and energy intake. It is unknown whether or not this finding has implications for energy intake control, but, if so, sufficient protein consumption may be more important than low fat intake. Dietary recommendations are not in line with this finding, because these emphasise the importance of reduced fat intake ${ }^{(36)}$.

In the present study, no association between the relative intake of fat and body composition was found. A positive association, however, was expected because a higher relative intake of fat was associated with a higher total energy intake, and because several other studies have found positive associations between fat intake and the gain in body weight ${ }^{(25-27)}$. In these studies, however, the positive association was not found in all subjects, but only in sedentary and genetically predisposed obese subgroups, or it was observed only for certain types of fat. The relatively small size of our sample unfortunately disabled the execution of stratified analyses on these factors.

Given the inverse associations between protein intake and overall energy intake, and no association between protein intake and physical activity, a more negative energy balance is presumed in subjects with a relatively high protein intake. Therefore, inverse associations were expected also between protein intake and skinfold thickness. Here, however, nonsignificant positive trends were found. This unexpected finding is even stronger for our data on high body fatness, where in both men and women the energy intake from protein was positively related to total fat mass at the age of 36 years. The higher precision and validity in estimating body fatness using dual-energy $\mathrm{X}$-ray absorptiometry measurements as compared with using skinfold thickness measurements may explain this difference in statistical significance found between the two methods ${ }^{(37)}$.

One explanation for the apparent inconsistency that subjects with a relatively high protein intake have a lower total energy intake and at the same time a higher body fatness could be that these subjects are also the ones with the lower levels of physical activity. In men indeed, but not in women, an inverse association between En\% from protein and physical activity was found. This inverse association in men, however, was small and not significant and therefore can only to a minor degree explain the positive associations of En\% from protein with adult body fat percentage. The absence of an inverse association between En\% from protein with the sum of skinfolds could not be caused by a confounding effect of physical activity, because this was adjusted for in the analyses. A confounding effect of the BMR can be another explanation of the positive association between protein intake and the body fat indices. 

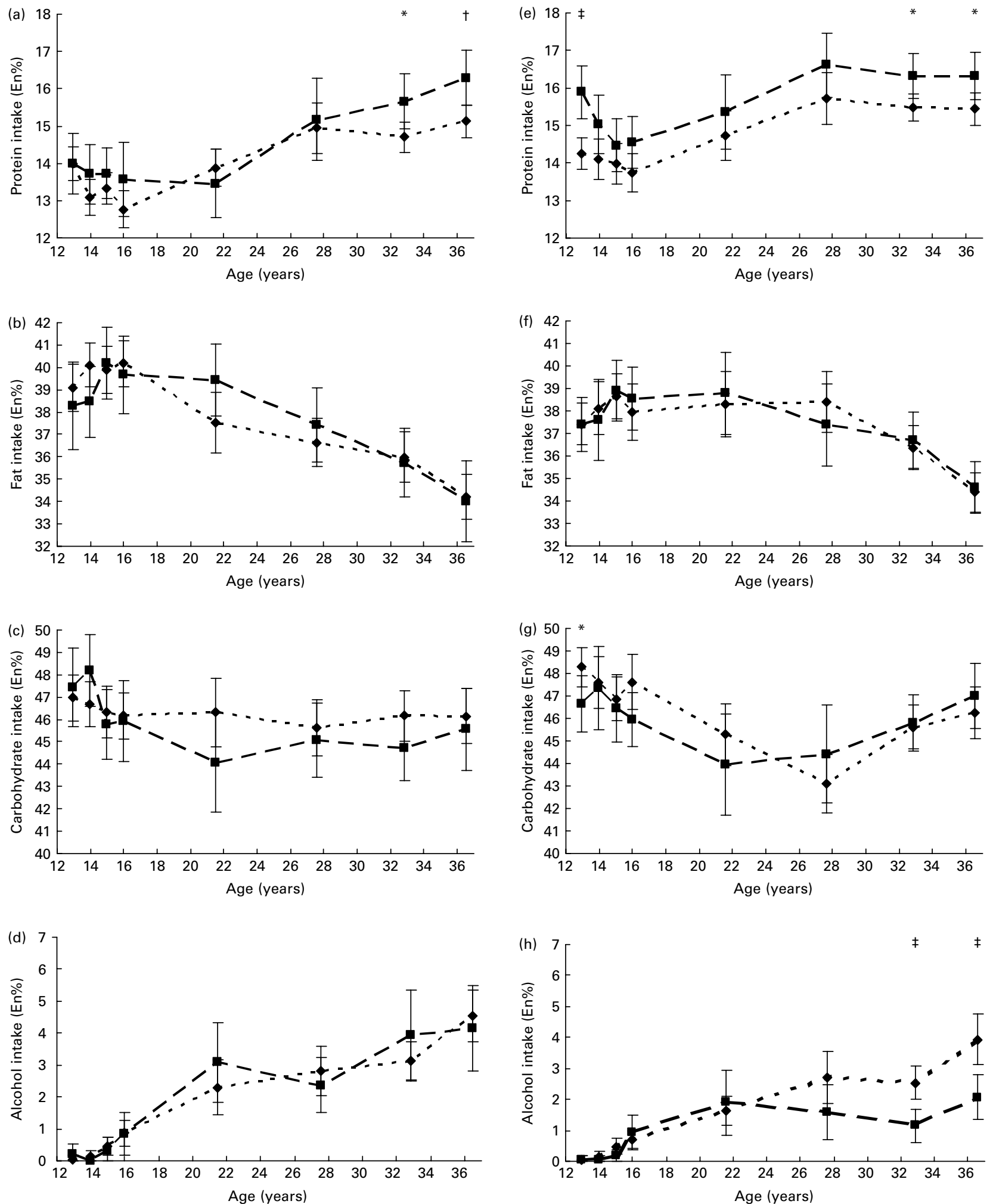

Fig. 1. Development (calculated with generalised estimating equation regression analyses) from mean age 13 to 36 years of energy intake in the form of protein, fat, carbohydrates and alcohol as percentages of total energy (En\%) intake in men ( $n$ 168; a-d) and women ( $n$ 182; e-h) stratified for high $\left(--\mathbf{a}_{-}-\right.$) and low (-- - ) percentage body fat at the mean age of 36 years. Participants were classified as having high body fatness if their percentage body fat exceeded $25 \%$ for men or $35 \%$ for women. Values are means, with $95 \% \mathrm{Cl}$ represented by vertical bars. Mean values were significantly different: ${ }^{\star} P<0.05$, $\dagger P<0.01, \ddagger P<0.001$. 
Table 3. Energy intake, physical activity and lean body mass in men and women with and without a high percentage of body fat at the mean age of 36 years (Mean values and standard deviations)

\begin{tabular}{|c|c|c|c|c|c|c|c|c|c|c|}
\hline \multirow{3}{*}{ Body fat... } & \multicolumn{5}{|c|}{ Men (n 119) } & \multicolumn{5}{|c|}{ Women (n 122) } \\
\hline & \multicolumn{2}{|c|}{$<25 \%$} & \multicolumn{2}{|c|}{$>25 \%$} & \multirow[b]{2}{*}{$P^{*}$} & \multicolumn{2}{|c|}{$<35 \%$} & \multicolumn{2}{|c|}{$>35 \%$} & \multirow[b]{2}{*}{$P^{*}$} \\
\hline & Mean & SD & Mean & SD & & Mean & SD & Mean & SD & \\
\hline Energy intake (MJ/d) & $12 \cdot 5$ & $3 \cdot 1$ & $11 \cdot 2$ & $2 \cdot 7$ & 0.02 & $9 \cdot 6$ & 1.9 & $8 \cdot 9$ & $2 \cdot 1$ & 0.03 \\
\hline Physical activity (kMET×h/week) & $4 \cdot 6$ & $2 \cdot 8$ & $3 \cdot 6$ & $2 \cdot 6$ & 0.04 & $5 \cdot 1$ & $3 \cdot 0$ & $6 \cdot 1$ & 4.5 & 0.07 \\
\hline Lean body mass $(\mathrm{kg})$ & $65 \cdot 3$ & 5.9 & 64.9 & $7 \cdot 9$ & 0.74 & $45 \cdot 9$ & $5 \cdot 6$ & $44 \cdot 6$ & $4 \cdot 8$ & 0.11 \\
\hline
\end{tabular}

MET, metabolic equivalents.

${ }^{*}$ By $t$ test.

Our finding that a higher protein intake is associated with a high body fat percentage is not in line with previous investigations, as most of these investigations show beneficial effects of high-protein and low-fat and -carbohydrate diets during weight loss and weight maintenance ${ }^{(3-7,14)}$. These studies, however, were short-term intervention trials in overweight populations with weight loss as a primary endpoint, whereas we investigated the associations of the four macronutrients over a longer period of energy balance in a general free-living population. The difference between our finding and that of the trials therefore may be due to the weight status of the subjects, the absolute amount of protein consumed, or due to the much longer period of follow-up in the present study.

Another explanation of our finding that a higher protein intake is associated with a high body fat percentage could be the fact that individuals with a higher BMI tend to underestimate their energy intake and in particular their fat intake, leading to a higher relative protein and carbohydrate intake ${ }^{(38)}$. To get an indication of whether or not underreporting of dietary energy intake has been present in our sample we analysed the differences in energy intake, physical activity and lean body mass between the groups with and without a high percentage of body fat at the age of 36 years. In both men and women, energy intake was lower in the groups with a high body fat percentage, suggesting an obesity-specific underreporting. In men with a high body fat percentage, however, this lower energy intake can be explained by lower energy requirements, as their physical activity level was lower also, whereas lean body mass -an indicator of the energy requirement for basal metabolismdid not differ between those with and without high body fat percentage. In women, the lower energy intake in the group with high body fatness may be explained by lower energy requirements for basal metabolism, as a $1.3 \mathrm{~kg}$ difference in lean body mass was found. On the other hand, the physical activity level in women with high body fat percentage was $20 \%$ higher than in women with a low body fat percentage. Even though it is not clear what the relative contributions of basal metabolism and physical activity are to total energy requirements, these findings suggest that obesity-specific underreporting of energy intake (which may be combined with over-reporting of physical activity) could explain for women, but not for men, the higher protein intake in those with a high body fat percentage.

In men, only at the ages of 32 and 36 years the relative protein intake was related to body fat at the age of 36 years. Elsewhere ${ }^{(39)}$ we have shown that the average BMI of the high percentage body fat group was above $25 \mathrm{~kg} / \mathrm{m}^{2}$ from age 32 years onwards. The AGAHLS participants were given feedback about their (over)weight status. Knowing that they belonged to the 'overweight' group may have resulted in a dietary change in macronutrient distribution. Employing a slightly changed dietary habit over a period of 4 years could have had these effects on body fatness. Knowing that they belonged to the 'overweight' group may also have resulted in a change of the way these men responded in the dietary history interview, with the present findings as a result. Reverse causality, therefore, can be an explanation of the association between protein intake and body fat percentage in men.

Women with a high body fat percentage at the age of 36 years were found to have a lower intake of alcohol at the ages of 32 and 36 years than women with a lower percentage of body fat. This finding may be explained by alcohol abstention or moderation as a means of weight reduction by the women with high body fatness, or by underreport of alcohol consumption by these women, for example due to socially desirable answering. The inverse association found between alcohol consumption and the physical activity level makes it unlikely that a difference in physical activity levels can explain why women with a high body fat percentage drink less alcohol.

In summary, a higher relative protein and (in men) carbohydrate intake and a lower relative intake of fat are associated with a lower total energy intake. These findings support the view that the energy density of the diet is associated with energy intake. In apparent contrast to the relationships we observed between protein intake and overall energy intake, male and female subjects with a high body fat percentage at the age of 36 years had a higher intake of protein at the ages of 32 and 36 years. These results are in contrast with previous investigations showing beneficial effects on body weight of a relatively high protein intake and a relatively low intake of fat and carbohydrate during and after weight loss. The difference in study findings may be related to the weight status of the subjects, and to the fact that we looked at the more long-term associations of differences in macronutrient intake in individuals who have ad libitum access to food. In women, obesity-specific underreporting of energy intake in the form of fat may also have caused our unexpected positive association between protein intake and body-fat indices. 


\section{Acknowledgements}

L. L. J. K., N. B., W. vM. and W. H. M. S. brought up the idea for the analyses. L. L. J. K. and A. C. J. N. analysed the data. L. L. J. K. and N. B. drafted the manuscript. W. vM. is the principal investigator of AGAHLS. All authors were involved in interpreting the data and contributed to the writing of the manuscript. None of the authors had any conflict of interest. There were no sources of funding.

\section{References}

1. World Health Organization (2003) Diet, Nutrition and the Prevention of Chronic Diseases. Joint WHO/FAO Expert Consultation. WHO Technical Report Series no. 916. Geneva: WHO.

2. Saris WH \& Tarnopolsky MA (2003) Controlling food intake and energy balance: which macronutrient should we select? Curr Opin Clin Nutr Metab Care 6, 609-613.

3. Farnsworth E, Luscombe ND, Noakes M, Wittert G, Argyiou E \& Clifton PM (2003) Effect of a high-protein, energy-restricted diet on body composition, glycemic control, and lipid concentrations in overweight and obese hyperinsulinemic men and women. Am J Clin Nutr 78, 31-39.

4. Eisenstein J, Roberts SB, Dallal G \& Saltzman E (2002) Highprotein weight-loss diets: are they safe and do they work? A review of the experimental and epidemiologic data. Nutr Rev 60, 189-200.

5. Baba NH, Sawaya S, Torbay N, Habbal Z, Azar S \& Hashim SA (1999) High protein vs high carbohydrate hypoenergetic diet for the treatment of obese hyperinsulinemic subjects. Int $J$ Obes Relat Metab Disord 23, 1202-1206.

6. Skov AR, Toubro S, Ronn B, Holm L \& Astrup A (1999) Randomized trial on protein vs carbohydrate in ad libitum fat reduced diet for the treatment of obesity. Int $J$ Obes Relat Metab Disord 23, 528-536.

7. Whitehead JM, McNeill G \& Smith JS (1996) The effect of protein intake on $24 \mathrm{~h}$ energy expenditure during energy restriction. Int J Obes Relat Metab Disord 20, 727-732.

8. Johnston CS, Day CS \& Swan PD (2002) Postprandial thermogenesis is increased $100 \%$ on a high-protein, low-fat diet versus a high-carbohydrate, low-fat diet in healthy, young women. $J$ Am Coll Nutr 21, 55-61.

9. Mikkelsen PB, Toubro S \& Astrup A (2000) Effect of fatreduced diets on $24 \mathrm{~h}$ energy expenditure: comparisons between animal protein, vegetable protein, and carbohydrate. Am J Clin Nutr 72, 1135-1141.

10. Westerterp KR, Wilson SA \& Rolland V (1999) Diet induced thermogenesis measured over $24 \mathrm{~h}$ in a respiration chamber: effect of diet composition. Int J Obes Relat Metab Disord 23, 287-292.

11. Robinson SM, Jaccard C, Persaud C, Jackson AA, Jequier E \& Schutz Y (1990) Protein turnover and thermogenesis in response to high-protein and high-carbohydrate feeding in men. Am J Clin Nutr 52, 72-80.

12. Poppitt SD, McCormack D \& Buffenstein R (1998) Short-term effects of macronutrient preloads on appetite and energy intake in lean women. Physiol Behav 64, 279-285.

13. Stubbs RJ, van Wyk MC, Johnstone AM \& Harbron CG (1996) Breakfasts high in protein, fat or carbohydrate: effect on withinday appetite and energy balance. Eur J Clin Nutr 50, 409-417.

14. Westerterp-Plantenga MS, Lejeune MP, Nijs I, van Ooijen M \& Kovacs EM (2004) High protein intake sustains weight maintenance after body weight loss in humans. Int J Obes Relat Metab Disord 28, 57-64.

15. Liddle RA, Green GM, Conrad CK \& Williams JA (1986) Proteins but not amino acids, carbohydrates, or fats stimulate cholecystokinin secretion in the rat. Am J Physiol Gastrointest Liver Physiol 251, G243-G248.

16. Bowen J, Noakes M, Trenerry C \& Clifton PM (2006) Energy intake, ghrelin, and cholecystokinin after different carbohydrate and protein preloads in overweight men. J Clin Endocrinol Metab 91, 1477-1483.

17. Foster GD, Wyatt HR, Hill JO, McGuckin BG, Brill C, Mohammed BS, Szapary PO, Rader DJ, Edman JS \& Klein S (2003) A randomized trial of a low-carbohydrate diet for obesity. N Engl J Med 348, 2082-2090.

18. Lean ME, Han TS, Prvan T, Richmond PR \& Avenell A (1997) Weight loss with high and low carbohydrate $1200 \mathrm{kcal}$ diets in free living women. Eur J Clin Nutr 51, 243-248.

19. Yancy WS Jr, Olsen MK, Guyton JR, Bakst RP \& Westman EC (2004) A low-carbohydrate, ketogenic diet versus a low-fat diet to treat obesity and hyperlipidemia: a randomized, controlled trial. Ann Intern Med 140, 769-777.

20. Astrup A, Grunwald GK, Melanson EL, Saris WH \& Hill JO (2000) The role of low-fat diets in body weight control: a meta-analysis of ad libitum dietary intervention studies. Int J Obes Relat Metab Disord 24, 1545-1552.

21. Astrup A, Ryan L, Grunwald GK, Storgaard M, Saris W, Melanson E \& Hill JO (2000) The role of dietary fat in body fatness: evidence from a preliminary meta-analysis of ad libitum low-fat dietary intervention studies. Br J Nutr 83, Suppl. 1, S25-S32.

22. Wannamethee SG \& Shaper AG (2003) Alcohol, body weight, and weight gain in middle-aged men. Am J Clin Nutr 77, $1312-1317$.

23. Koppes LLJ, Twisk JWR, Van Mechelen W, Snel J \& Kemper HCG (2005) Cross-sectional and longitudinal relationships between alcohol consumption and lipids, blood pressure and body weight indices. J Stud Alcohol 66, 713-721.

24. Maskarinec G, Takata Y, Pagano I, Carlin L, Goodman MT, Le Marchand L, Nomura AM, Wilkens LR \& Kolonel LN (2006) Trends and dietary determinants of overweight and obesity in a multiethnic population. Obesity 14, 717-726.

25. Heitmann BL, Lissner L, Sørensen TI \& Bengtsson C (1995) Dietary fat intake and weight gain in women genetically predisposed for obesity. Am J Clin Nutr 61, 1213-1217.

26. Lissner L, Heitmann BL \& Bengtsson C (1997) Low-fat diets may prevent weight gain in sedentary women: prospective observations from the population study of women in Gothenburg, Sweden. Obes Res 5, 43-48.

27. Field AE, Willett WC, Lissner L \& Colditz GA (2007) Dietary fat and weight gain among women in the Nurses' Health Study. Obesity 15, 967-976.

28. Kemper HCG (2004) Amsterdam Growth and Health Longitudinal Study (AGAHLS): a 23-Year Follow-up from Teenager to Adult About Lifestyle and Health. Medicine and Sport Science, vol. 47. Basel: Karger.

29. Post GB (1989) Nutrition in Adolescence: A Longitudinal Study in Dietary Patterns from Teenager to Adult. Haarlem, The Netherlands: De Vrieseborch.

30. Bakker I, Twisk JW, van Mechelen W, Mensink GB \& Kemper HC (2003) Computerization of a dietary history interview in a running cohort; evaluation within the Amsterdam Growth and Health Longitudinal Study. Eur J Clin Nutr 57, 394-404.

31. Voorlichtingsbureau voor de Voeding (Netherlands Nutrition Centre) (1996) NEVO Table (Dutch Food Composition Chart). Den Haag: Stichting Nederlands Voedingsstoffenbestand.

32. Kemper HCG, Twisk JWR, Koppes LLJ, Van Mechelen W \& Post GB (2001) A 15-year physical activity pattern is positively related to aerobic fitness in young males and females (13-27 years). Eur J Appl Physiol 84, 395-402.

33. Weiner JS \& Lourie JA (1969) Human Biology, a Guide to Field Methods. IBP Handbook. Oxford: Blackwell. 
34. Twisk JWR (2003) Applied Longitudinal Data Analysis for Epidemiology: a Practical Guide. Cambridge, UK: Cambridge University Press.

35. Jebb SA (2005) Dietary strategies for the prevention of obesity. Proc Nutr Soc 64, 217-227.

36. Astrup A (1999) Macronutrient balances and obesity: the role of diet and physical activity. Public Health Nutr 2, 341-347.

37. van Marken Lichtenbelt WD, Hartgens F, Vollaard NB, Ebbing S \& Kuipers H (2004) Body composition changes in bodybuilders: a method comparison. Med Sci Sports Exerc 36, 490-497.
38. Goris AH, Westerterp-Plantenga MS \& Westerterp KR (2000) Undereating and underrecording of habitual food intake in obese men: selective underreporting of fat intake. Am J Clin Nutr 71, 130-134.

39. Nooyens ACJ, Koppes LLJ, Visscher TLS, Twisk JWR, Kemper HCG, Schuit AJ, van Mechelen W \& Seidell JC (2007) Adolescent skinfold thickness is a better predictor of high body fatness in adults than is body mass index: the Amsterdam Growth and Health Longitudinal Study. Am J Clin Nutr 85, $1533-1539$. 